\title{
Self-Reported Prevalence of Osteoporosis in Australia
}

\author{
Tiffany K. Gill1, Anne W. Taylor ${ }^{1}$, \\ Julie Black ${ }^{2}$ and Catherine L. Hill 1 \\ ${ }^{1}$ University of Adelaide, \\ ${ }^{2}$ Arthritis $S A$ \\ Australia
}

\section{Introduction}

"Self-report" is generally the only method of determining the prevalence of non-registry based chronic diseases (Bergmann et al., 2004). However, there are difficulties in "case definition" associated with self-report and often the most effective means of identifying the presence of disease is to determine whether the chronic condition in question has been diagnosed by the doctor. Chronic conditions such as osteoporosis are often difficult to identify as they do not generally manifest themselves until after a bone fracture occurs. The aim of this chapter is to determine the self-reported prevalence of osteoporosis and associated demographic factors from a community dwelling sample aged 15 years and over across a 16 year period and compare this prevalence with that obtained from a biomedical study. Associated risk and demographic factors can be examined using these data. The issues around the use of self-reported, doctor-diagnosed osteoporosis to determine disease prevalence will also be discussed.

\section{Background}

Osteoporosis is a hidden condition. Bone loss due to osteoporosis is subtle but as there are no overt symptoms, it is generally not until a fracture occurs that osteoporosis may be identified (Australian Institute of Health and Welfare [AIHW] 2011; Rachner et al., 2011; Sànchez-Riera et al., 2010). However, with an ageing population, the related medical issues and socioeconomic impact will only increase (Rachner et al., 2011). Osteoporosis is a condition which affects both men and women although the greatest focus has generally been on post menopausal women (Cawthon, 2011). A meta-analysis identified that there was a five to eight fold increase in the risk of mortality due to all causes within the first three months following a hip fracture (Haentjens et al., 2010), which is a common fracture type associated with osteoporosis (Cooper, 1997). An increased annual mortality remains over time and it is generally higher for men compared to women (Center et al., 2011; Haentjens et al., 2010). Fractures consequently are a significant health issue which lead to not only premature mortality but also an increased level of disability and risk of future fracture (Center et al., 2007; Center et al., 2011; Cooper, 1997). 
Dual x-ray absorptiometry (DXA) is considered to be the gold standard for the diagnosis of osteoporosis (Keen, 2007). Guidelines have been developed and implemented to address effectively screening for osteoporosis (Rachner et al., 2011). In Australia, the guideline focuses on post menopausal women and older men (Royal Australian College of General Practitioners, 2010), as do other international guidelines (Compston et al., 2009; Hodgson et al., 2003). The guideline does not, however, come into effect until there has been a minimal trauma fracture (Royal Australian College of General Practitioners, 2010). Risk assessment tools have also been developed which combine clinical risk factors and DXA measurements (Borgström \& Kanis, 2008; Unnanuntana et al., 2010). Thus DXA scans are only provided to those considered at risk of osteoporosis or in response to a minimal trauma fracture. Bone density screening is not provided to the population in a similar manner to breast cancer screening, as it is not considered cost effective, due to the cost of providing scans and limited availability (Davis et al., 2011).

A variety of data sources are used to determine the characteristics of osteoporosis within the Australian population and estimating the population prevalence can be difficult. Selfreported, doctor diagnosis of a condition is generally used in population surveys but these estimates do not generally reflect the true prevalence. This discrepancy with true prevalence has been demonstrated (Sacks et al., 2005) using arthritis information collected as part of the Behavioural Risk Factor Surveillance System (BRFSS) which is undertaken across the United States. In terms of osteoporosis, the prevalence is underestimated due to the absence of obvious symptoms until a diagnosis may occur following a minimal trauma fracture (AIHW, 2011; Werner, 2003). But even after a minimal trauma fracture, those with osteoporosis may be untreated or undiagnosed (Eisman et al., 2004) or the underlying disease may not be appropriately investigated (Elliot-Gibson et al., 2004).

Osteoporosis contributes to the global burden of disease. Chronic conditions (including osteoporosis), whether they are physical or mental, reduce quality living time, with the subsequent morbidity significantly impacting the population (McQueen, 2003). Regular surveillance allows the monitoring of health, demographic and other related data to assess trends and prevalence and also provide an explanation of demographic and exposure differences, the use of health services and evaluate if there is a response to health promotion and public health interventions (McQueen, 2003; Wilson, 2003). A system that monitors chronic disease and related risk factors does have some specific features which characterise it as "surveillance" (Campostrini, 2003). These include:

- Time, which is a essential element of the data collection,

- There is a focus on chronic or non-communicable diseases and related factors, and

- Attention is also focused on the data management, collection, analysis, use and interpretation (Campostrini, 2003).

While it is considered most ideal to collect data across short timeframes (e.g. a day, a week or a month) in order to simulate as closely as possible a continuous data collection, this is not always practical or feasible (Campostrini, 2003; McQueen, 2003). However, if questions and methodology remain stable over time so that changes or trends that occur can be attributed to true population changes and not questionnaire changes, and data are collected at regular intervals (McQueen, 2003); the information provided is extremely powerful.

Developing a systematic approach to surveillance addresses many needs. These include: an estimation of the size of the problem, the geographic distribution, detection of an epidemic or definition of a problem, stimulation of research and research hypotheses, monitoring changes in disease patterns and providing assistance to planning. Population-based 
information related to economic, social, cultural and physical factors which are relevant to health can be provided. These factors can then be associated with the effects of public health and health promotion interventions and targeted campaigns. Data on health risk factors can also be obtained and support afforded to health related legislative programs and disease prevention actions, and regular surveillance can also evaluate the long term effects of health promotion campaigns. Also, future trends, the use of health resources and the emergence of any new health issues can be recognised (International Union for Health Promotion and Education World Alliance for Risk Factor Surveillance Global Working Group [IUHPE WARFS GWG], 2011).

Thus, while self-report underestimates osteoporosis prevalences, use of this method of data collection can improve the understanding and knowledge of the disease, in addition to assisting the identification of high risk groups (Werner, 2003). Self-report has been used in population surveys in South Australia (SA), Australia for approximately 20 years, with osteoporosis data being collected since 1995. Questions have been asked in the same way, using the same methodology annually, and while this timeframe is considered to be infrequent in terms of the surveillance timeframe spectrum (IUHPE WARFS GWG, 2011), aggregated data from these surveys possess the characteristics of a more regular surveillance system. Aggregation of these data provides the ability to analyse data over time and enables an assessment of changes in prevalence over the period of time under examination. It also provides evidence for the development of policy and an investigation of the impact of these policies over time.

\section{Methods}

The data presented in this chapter are derived from two different sources. The first is a faceto-face survey and the second, a telephone survey and clinical assessment conducted as part of a longitudinal cohort study.

\subsection{Health Omnibus Survey (HOS)}

The self-reported prevalence of osteoporosis has been collected in SA since 1995, using the SA Health Omnibus Survey (SAHOS) which is conducted annually, with data collection between September and December each year (spring to summer in Australia). Key uses of the survey are:

- gaining information on knowledge, attitudes and behaviours;

- gaining information on perceptions towards, and acceptability of, services and programs or organisations;

- $\quad$ provision of prevalence or incidence data;

- explaining population perspectives, attitudes, values and behaviours associated with issues under investigation;

- allowing the segmentation of problems and related issues;

- identifying target groups for interventions and campaigns;

- monitoring changes in health problems and disease trends;

- gaining information on the acceptability and uptake of new initiatives and programs;

- obtaining information on the aetiology of specific health problems;

- obtaining data to test hypotheses; and

- evaluating interventions and programs. 
Questions to be included in each survey are reviewed by a quality control committee, both before and after pilot testing, for appropriate wording and design. Approximately ten background demographic questions are included within the survey. SAHOS is a face-to-face survey, which is the original method and consequently the "gold standard" of interview techniques (Dillman, 1999; Dillman et al., 2009; Schonlau et al., 2002). Participation is voluntary. Interviewers read out the questions to participants and, if necessary, prompt cards are used to ensure that respondents remember all of the response categories. The questionnaire is designed to take approximately 30 to 40 minutes for respondents to complete. Prior to the main survey, a pilot study of 50 interviews is conducted to test questions, validate the survey instrument and assess survey procedures.

\subsubsection{Sample size}

The survey sample is a clustered, multi-stage, systematic, self-weighting, area sample. Each of these key sampling concepts is described in more detail below. Each survey usually samples 5,200 households. The SAHOS has been in operation since 1991 and since that time the observed response rate has generally ranged between approximately $60-70 \%$, usually resulting in a minimum of 3,000 interviews being completed each year. This large sample size facilitates a high level of confidence that the results and trends obtained in response to the survey questions can be extrapolated to the South Australian population as a whole.

\subsubsection{Clustered sample}

Seventy-five percent of the sample is selected from from the metropolitan area of the capital, Adelaide, with the remaining sample being drawn from those country areas with a population of 1,000 or more (based on Australian Bureau of Statistics (ABS) Census information which is collected every five years in Australia). Country towns with smaller populations are not included within the sample frame because of the additional cost of interviewing people living in these remote areas. Within the selected metropolitan and country areas, the ABS Collection Districts (CDs) are the basis of the sample frame. A CD is a geographical area comprising approximately 200 dwellings. By using a cluster sampling technique, some, but not all, of these CDs are included in the sample. To achieve a sample of 5,200 households, 10 households are selected from each of 520 CDs.

\section{Stage 1 - Selection of CDs}

Based on ABS population estimates, 400 CDs are selected in metropolitan Adelaide, and 120 CDs from the selected country areas. All cities/towns in country SA with a population size of 10,000 or more are selected automatically with the balance of the country sample chosen from centres with a population of 1,000 or more. A randomly selected starting point and a fixed skip interval are used to determine which CDs are chosen from the sample frame. The skip interval is calculated as the number of households in metropolitan Adelaide (or country $\mathrm{SA}$ ) divided by the number of CDs required for the metropolitan (or country) sector.

The process of selection is as follows. Firstly, all CDs in the sample frame are listed in numerical code order, along with the number of dwellings in that individual CD and the "cumulative number of dwellings" for that CD. The cumulative number of dwellings is defined as the total number of dwellings for a particular CD and all previously listed CDs. A random number between one and the skip number is chosen as the starting point for selections and the skip interval is then used to determine which CDs are selected. If, for 
example, the starting point is 80 and the skip interval is 100, then the CDs which contain the 80th, 180th and 280th cumulative dwelling will be the first three CDs to be selected. Thus, once the skip interval has been determined, selection of an individual CD is dependent on the number of dwellings within that CD. In some cases, larger CDs may, in theory, be selected more than once.

\section{Stage 2 - Selection of households within CDs}

The selection process of households is similar to the selection of CDs. Ten households per selected CD are chosen using a fixed skip interval from a random starting point.

\section{Stage 3 - Selection of individuals within households}

Within households, the person who was last to have a birthday (aged 15 years or over) is selected to participate in the survey. The sample is a non-replacement sample, thus, if the selected person is not available, interviews are not conducted with any other household members. Generally up to six visits are made to each household to interview the selected participant, before the selected individual is classified as a non-contact, however in some cases more visits may be conducted. Selections that occur in hotels, motels, hospitals, nursing homes and other institutions are excluded from the survey.

\subsubsection{Systematic sample}

The randomly selected starting points and the skip intervals between selected CDs and selected households within CDs produce a systematic even spread of households across the population.

\subsubsection{Self weighting sample}

The self-weighting sampling procedure of HOS ensures that every household within each of the two strata (metropolitan Adelaide and the major country towns) have the same probability of being selected even though different probabilities of selection exist at each stage of the sampling process.

The probability of selecting a household equals the probability of selecting a CD (i.e. the cumulative number of dwellings in the CD divided by the skip interval) multiplied by the probability of selecting a household, given that the $\mathrm{CD}$ was selected (i.e. the number of households required in each $\mathrm{CD}$ divided by the cumulative number of households in the CD).

\subsubsection{Approach letter}

In line with other epidemiologically-based surveillance systems, a letter introducing SAHOS is sent to each selected household including a brochure outlining how the information is used. It has been shown that sending a letter informing a person of a survey can increase response rates (Frey, 1989; Robertson et al., 2000). If respondents have any questions about the survey, they are able to call a free call telephone number listed in the approach letter.

\subsubsection{Validation}

Ten percent of all respondents are re-contacted and re-interviewed using selected questions to ensure the validity of the original responses. Data entry is fully verified using a double entry technique to ensure the accuracy of the final data. 


\subsubsection{Weighting}

All SAHOS data are weighted by age, sex, area of residence and the inverse of the probability of selection in the household to the most recent ABS Census or Estimated Residential Population data for SA.

\subsubsection{Ethics approval}

Ethics approval for the methodology of the survey is provided by the Human Research Ethics Committee of the University of Adelaide and ethics approval for questions may be provided through the individual users' institutions, or if users do not have access to a committee, by the University of Adelaide.

\subsubsection{Questions related to osteoporosis prevalence}

The methodology of the SAHOS has remained consistent over time and questions relating to self-reported, doctor diagnosed osteoporosis have been included since 1995, which enables examination of prevalence changes over time.

Questions within the SAHOS include demographic characteristics:

- Sex;

- Age;

- Country of birth;

- Marital status;

- Income (gross annual household income before tax in Australian dollars);

- Work status;

- Area of residence; and

- Year of survey.

The question used to determine osteoporosis prevalence is "Have you ever been told by a doctor that you have osteoporosis? “

\subsection{North West Adelaide Health Study}

The North West Adelaide Health Study (NWAHS) is a longitudinal cohort study of over 4,000 participants located in the northwest suburbs of Adelaide, SA, Australia.

The study focuses on priority health conditions and risk factors that have been identified due to the significant burden that is placed on the community in terms of social, health, quality of life and economic factors. By identifying and describing specific population groups at risk of chronic conditions, the effectiveness of strategies for the prevention, early detection, and management of chronic conditions may be maximised (Grant et al., 2006; Grant et al., 2009).

Participants were recruited to Stage 1 of the study between 2000 and 2003, and undertook a second assessment between 2004 and 2006. The initial objective of the study was to establish both baseline self-reported and biomedically measured information on chronic diseases and risk factors, in terms of those who may be at risk of these conditions, those who already had these conditions but had not been diagnosed, and those who had previously been diagnosed with the conditions. Identifying those categories of disease along a chronic disease continuum provides a view of disease burden and presents opportunities for effective interventions, improved health service use and development of health policy (Grant et al., 2006; Grant et al., 2009). When specifically considering osteoporosis, the chronic disease continuum can be described as presented in Figure 1. 


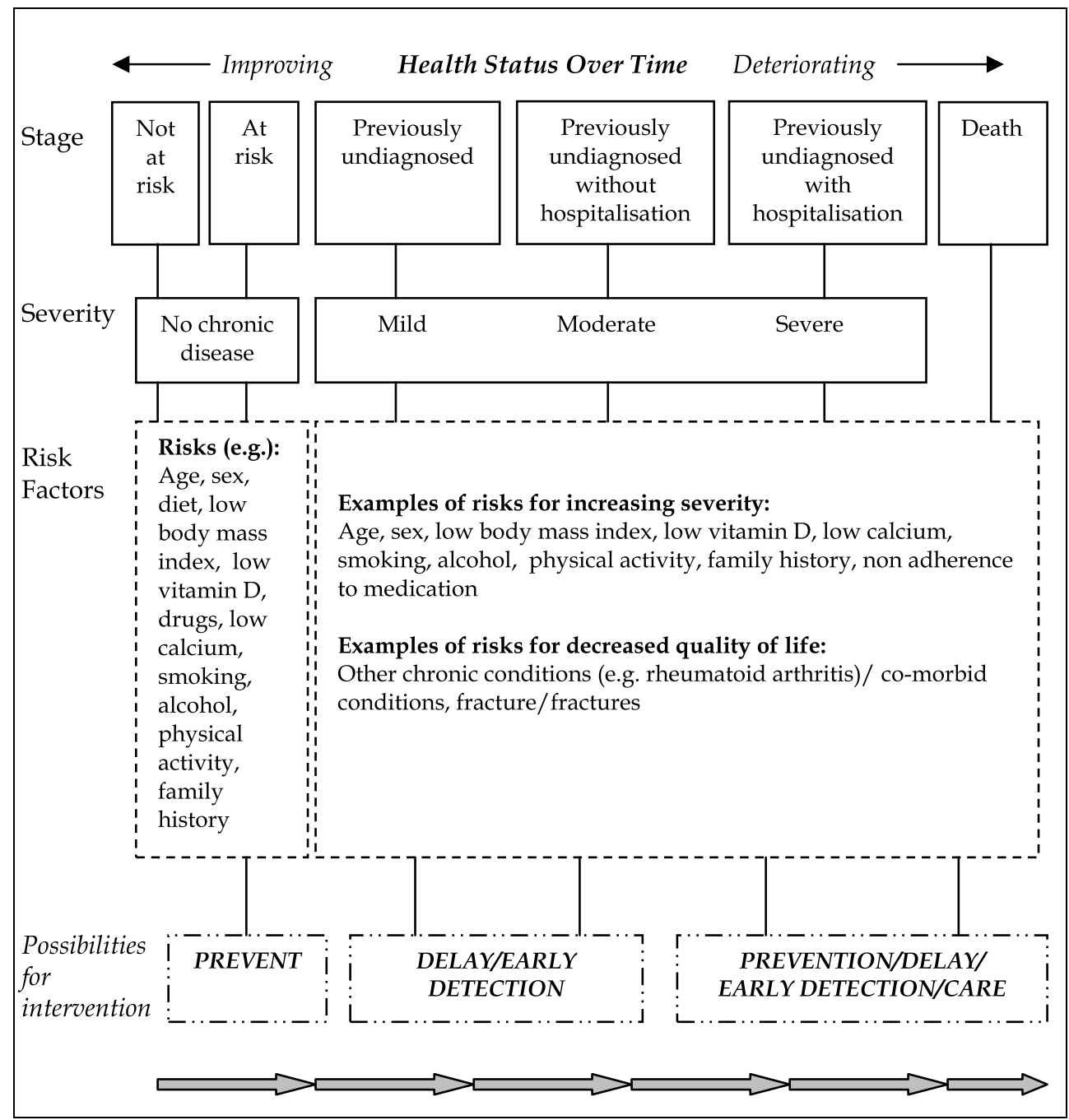

Fig. 1. Chronic Disease Continuum for Osteoporosis

\subsubsection{Stage one}

All households in the northern and western areas of Adelaide, SA, with a telephone connected and a telephone number listed in the Electronic White Pages were eligible for selection in the NWAHS. Households were randomly selected and sent an approach letter and brochure informing them about the study. The person who was last to have their birthday within each household and aged 18 years and over was selected for interview. Interviews were conducted using Computer Assisted Telephone Interview (CATI) technology.

During the telephone interview respondents were asked a range of health-related and demographic questions, and were invited to attend an assessment clinic for a 45 minute 
appointment at either of two local hospitals in Adelaide, one in the western suburbs and one in the northern suburbs. All study participants who agreed to attend the clinic were sent an information pack about the study, including a self-report questionnaire which examined other chronic conditions and health-related risk factors that were not included in the telephone interview.

During the clinic visit, the tests included: height, weight, waist and hip circumference, and blood pressure. Lung function was calculated and a fasting blood sample was taken to measure glucose, tryglycerides, total cholesterol, high density lipid (HDL), low density lipid (LDL), and glycated haemoglobin (HbA1c). The response rate for attending the clinic in Stage 1 was $49.4 \%$ with a final sample of $n=4056$.

\subsubsection{Stage two}

All participants that could be contacted, were invited to attend the clinic for Stage 2 using a telephone interview that also obtained demographic and health-related information. Of the original living cohort, over 90\% provided some Stage 2 information, and 3,205 (over 81.0\%) attended the clinic assessment between 2004 and 2006 for the second time. The minimum age of participants in Stage 2 was 20 years. In addition to the measurements taken at Stage 1 (which concentrated on the chronic conditions diabetes, chronic obstructive pulmonary disease and asthma), renal function and musculoskeletal conditions were also assessed. The musculoskeletal conditions included both arthritis and osteoporosis and a range of questions related to specific joint pain. Participants aged 50 years and over were offered a DXA scan to measure their bone density, and fat and lean body mass.

The longitudinal nature of the cohort study means that following Stage 2, valuable information was obtained relating to the number of people who had developed chronic conditions over the timeframe of the study and the factors that may have contributed to their risk of developing chronic disease. Stage 3 of the study has recently been completed with all respondents who could be contacted again being asked to attend the clinic for assessment and information relating to musculoskeletal conditions again included in the study. However the results in this chapter are limited to Stage 2 data only.

\subsubsection{Weighting}

Weighting was used to correct for the disproportionality of the original sample with respect to the population of interest. The data were weighted for age, sex, probability of selection in the household and area of residence. These weights reflect any unequal sample inclusion probabilities and compensate for differential non-response. The data were weighted using the ABS Census data so that the health estimates calculated would be representative of the adult populations of the north west area of Adelaide. Subsequently, each stage of the study is weighted with the initial sample weight as the foundation figure.

\subsubsection{Ethics approval}

Ethics approval for the each stage of the NWAHS has been granted by the Ethics of Human Research Committee of The Queen Elizabeth Hospital, Adelaide, SA.

\subsubsection{Questions related to osteoporosis prevalence}

Data collection methods for the NWAHS are a CATI, a self-complete questionnaire and a clinic assessment. Questions incorporated within the NWAHS include demographic characteristics: 
- Sex;

- Age;

- Country of birth;

- Marital status;

- Income (gross annual household income before tax in Australian dollars);

- Work status; and

- Area of residence.

The question used to determine osteoporosis prevalence is "Have you ever been told by a doctor that you have osteoporosis?" This information is collected as part of the CATI in Stage 2. Other information collected as part of the CATI was the self-reported occurrence of fractures following a fall from a standing height or less in the past year and self-reported types of arthritis, including rheumatoid and osteoarthritis (that is, "Have you ever been told by a doctor that you have arthritis?"). Those who responded in the affirmative were then asked what type of arthritis they had.

Other variables that are collected as part of the NWAHS were: family history of osteoporosis (mother, father, sister, brother, grandparent, other), self-reported smoking (which is categorised as current, ex- or non-smoker) and alcohol intake. Regarding alcohol intake, participants were asked how often they drank alcohol, and if they drank, on a day when they drank alcohol, how many drinks they usually had. They were then classified according to their level of risk of harm from alcohol, as non-drinkers or no risk, low alcohol risk, and intermediate to very high alcohol risk (National Heart Foundation of Australia, 1989). Physical activity level was also determined, respondents were asked about the amount of walking, moderate and vigorous activity they had undertaken in the past two weeks. These questions were the same as those used in the Australian National Health Survey in 2001 and 2004 (ABS, 2003, 2006), and the responses were classified into four activity levels (sedentary, low, moderate and high). All of these variables were obtained from the self-completed questionnaire.

Height and weight were measured as part of the clinic assessment to calculate body mass index and DXA scans were provided to those aged 50 years and over who consented to the scan and respondents were classified as having osteoporosis (T score $\leq-2.5)$ or osteopenia ($1.0<\mathrm{T}$ score $>-2.5)$ using the World Health Organization $(\mathrm{WHO})$ definition of osteoporosis (WHO, 1994). Overall 75.7\% of eligible participants undertook a DXA scan.

\subsection{Data analysis}

Analyses were conducted using SPSS Version 18 (IBM SPSS Statistics, New York, NY, USA) and STATA Version 11.2 (StataCorp, College Station, TX, USA).

\section{Results}

\subsection{Prevalence of osteoporosis (SAHOS)}

The self-reported prevalence of osteoporosis has been collected every year in SAHOS between 1995 and 2010 except in 1996 and 2000. Thus there are fourteen years of data available. The aggregated sample size was $n=41,487$. Overall, $49 \%$ of respondents were male and $51.0 \%$ female, with a mean age of 45.0 years (SD 18.85, range 15-102). The aggregated prevalence of self-reported osteoporosis among those aged 15 years and over, between 1995 and 2010, was $4.8 \%$ (95\% CI 4.6-5.0). 
The self-reported prevalence from SAHOS was then age and sex standardised to the 2006 Australian Census (ABS, 2007) to enable prevalence comparisons between years and the results are presented in Figure 2. Data points for 1996 and 2000 are not available as these years had missing data.

As the data were aggregated, autocorrelation may occur which violates the assumptions of linear analysis. A Durbin-Watson test was undertaken to determine if first order autocorrelation of the residuals of the annual prevalence estimates had occurred. The value was 1.73, close to 2 indicating that there was not excessive autocorrelation of the data (Chatfield, 2004; Yaffee \& McGee, 2000).

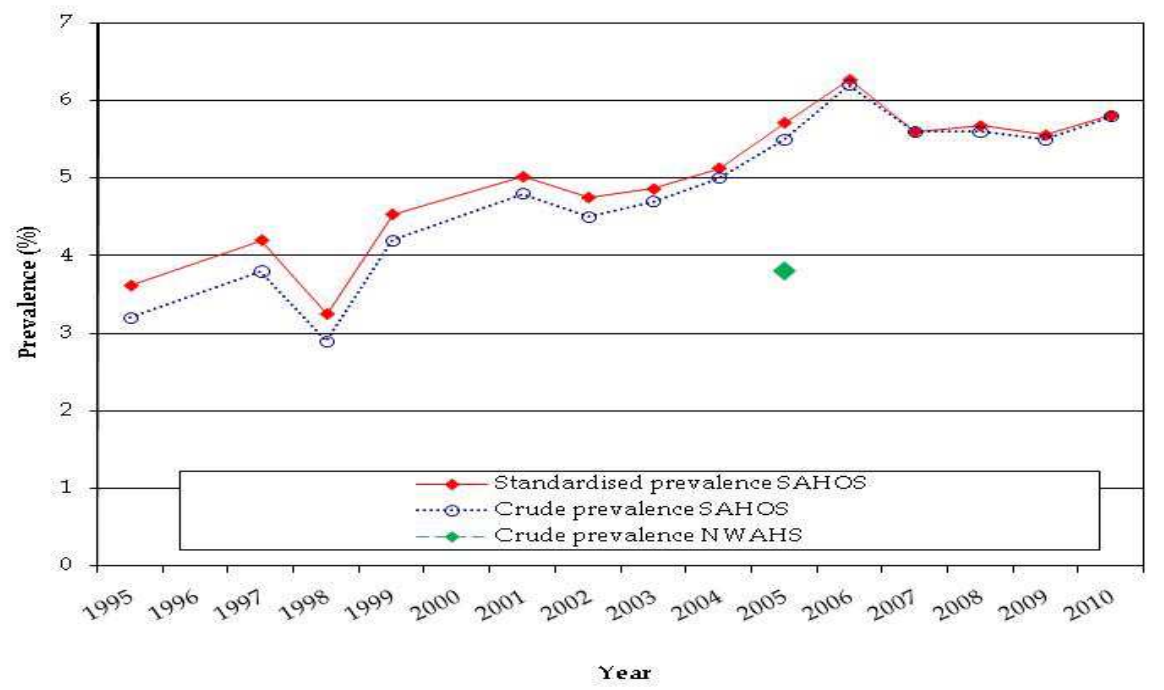

Fig. 2. Prevalence of self-reported osteoporosis from SAHOS and NWAHS

The data were examined to determine if a deviation from a linear trend existed. The regression coefficients were graphed and demonstrated an approximate straight line and a Box-Tidwell regression model was undertaken (Box \& Tidwell, 1962), which also indicated that the nonlinear deviation was not significant $(p=0.09)$. A chi-square test for trend was then conducted, which indicated that there had been a significant change in the selfreported osteoporosis prevalence over time $(\mathrm{p}<0.001)$.

\subsection{Prevalence of osteoporosis (NWAHS)}

Participants in Stage 2 of the NWAHS undertook one, two or all three of the data collection methods (CATI, self-complete questionnaire, clinic assessment) depending on their time constraints and desired level of participation. There were $n=3500$ respondents to the CATI questionnaire (49.1\% male and 50.9\% female; mean age 47.42, SD 17.57, range 20-93), n=3259 responded to the self-complete questionnaire $(49.1 \%$ male and $50.9 \%$ female; mean age 47.59 , SD 17.51, range 20-95) and $n=3205$ attended the clinic (49.1\% male and 50.9\% female; mean age 47.58, SD 17.52, range 20-95). The self-reported prevalence of osteoporosis among participants in the NWAHS aged 20 years and over during Stage 2 (2004 to 2006) was 3.8\% (95\% CI 3.2-4.5). The crude prevalence of osteoporosis obtained from the NWAHS is shown in Figure 2. 


\subsection{Logistic regression analyses}

Logistic regression analysis of the aggregated SAHOS data set was then undertaken in order to determine the demographic characteristics most likely to be associated with self-reporting the presence of osteoporosis. Data for these analyses were restricted to respondents aged 20 years and over to enable comparisons with the NWAHS data. The variables included in the analysis were: age, sex, country of birth, income, education, marital status and work status. Area of residence was not included as SAHOS is a state wide sample and NWAHS is a metropolitan sample. Bivariate and then multivariate logistic regression analyses were conducted to identify the best sets of explanatory variables associated with osteoporosis, with variables that were significant at $\mathrm{p}<0.25$ in the bivariate analysis included in the multivariate model, as these may still be candidates for model predictors - they can continue to be a good fit when other variables are included in the model (Hosmer \& Lemeshow, 2000). Then the non-significant variables at $p \geq 0.05$ were removed until all remaining variables were significant. Finally, all models were tested for "goodness of fit" using the Hosmer and Lemeshow goodness of fit test (Hosmer \& Lemeshow, 2000).

Analysis of the demographic variables associated with self-reported osteoporosis for the SAHOS and NWAHS produced similar factors, with increasing age, sex (female) and work status (unemployed, retired and "other") significant for both datasets (Table 1). In the SAHOS, those who reported that they undertook home duties were also significantly more likely to report that they had osteoporosis. Those earning between $\$ 12,001$ and $\$ 50,000$, were also significantly more likely to self-report osteoporosis in the SAHOS, whereas this variable was not significant for those self-reporting osteoporosis in the NWAHS.

A model was then created for the SAHOS data only, to examine the impact of time. The variables associated with self-reporting osteoporosis were: increasing age, sex (female), work status (unemployed, retired and "other", home duties), income (up to $\$ 50,000$ and not stated) and year, with more recent years associated with higher self-reported prevalence of osteoporosis (data not shown).

The self-reported prevalences collected as part of the SAHOS and the NWAHS were then compared to the prevalence of osteoporosis and osteopenia as defined in the NWAHS using DXA scans. DXA scans were only undertaken on those aged 50 years and over, thus the analysis is limited to this age group. The aggregated prevalence of self-reported osteoporosis among those aged 50 years and over in SAHOS was 10.7\% (95\% CI 10.3-11.2) compared to $8.8 \%$ (95\% CI 7.5-10.3) for self-report in NWAHS and 18.7\% (95\% CI 16.6-20.9) for those classified with osteoporosis and osteopenia combined as defined by DXA scans (osteoporosis 3.6\% (95\% CI 2.6-4.9) and osteopenia 15.1\% (95\% CI 13.2-17.1)). It was considered appropriate to combine the categories of osteoporosis and osteopenia as both are indicators of abnormal bone density.

Bivariate and multivariate analyses were then undertaken for all participants aged 50 years and over. This second group of models included all of the demographic characteristics collected as part of both studies and examined the variables associated with self-report and clinically defined osteoporosis (Table 2). Increasing age and female sex were significant for all three models and again for SAHOS and self-reported osteoporosis from NWAHS, work status (unemployed and retired) was significant. Income was also significantly associated with self-reporting osteoporosis in SAHOS, while marital status (never married) was significantly associated with low bone density as defined by DXA scans. 


\begin{tabular}{|c|c|c|c|c|}
\hline \multirow[b]{2}{*}{ Group One } & \multicolumn{2}{|c|}{ SAHOS self-report } & \multicolumn{2}{|c|}{ NWAHS self-report } \\
\hline & OR & $\mathrm{p}$-value & OR & $\mathrm{p}$-value \\
\hline \multicolumn{5}{|l|}{ Sex } \\
\hline Male & 1.00 & & 1.00 & \\
\hline Female & 3.76 & $<0.001$ & 5.55 & $<0.001$ \\
\hline Age & 1.06 & $<0.001$ & 1.06 & $<0.001$ \\
\hline \multicolumn{5}{|l|}{ Work status } \\
\hline Full time & 1.00 & & 1.00 & \\
\hline Part time & 1.13 & 0.432 & 1.48 & 0.430 \\
\hline Home duties & 1.47 & 0.009 & 1.16 & 0.866 \\
\hline Unemployed & 2.05 & 0.024 & 3.25 & 0.015 \\
\hline Retired & 1.44 & 0.015 & 2.95 & 0.037 \\
\hline Student & 1.40 & 0.436 & - & - \\
\hline Other & 5.65 & $<0.001$ & 4.43 & 0.020 \\
\hline Not stated & - & - & 4.84 & 0.108 \\
\hline \multicolumn{5}{|l|}{ Income } \\
\hline$\$ 80,001$ and more & 1.00 & & & \\
\hline$\$ 60,001-\$ 80,000$ & 1.41 & 0.108 & & \\
\hline$\$ 50,001-\$ 60,000$ & 1.23 & 0.362 & & \\
\hline$\$ 40,001-\$ 50,000$ & 1.80 & 0.004 & & \\
\hline$\$ 30,001-\$ 40,000$ & 1.61 & 0.022 & & \\
\hline$\$ 20,001-\$ 30,000$ & 1.68 & 0.006 & & \\
\hline$\$ 12,001-\$ 20,000$ & 1.72 & 0.004 & & \\
\hline Up to $\$ 12,000$ & 1.33 & 0.129 & & \\
\hline Not stated & 1.31 & 0.146 & & \\
\hline
\end{tabular}

Table 1. Logistic regression analysis of self-report osteoporosis, SAHOS and NWAHS, age 20 years and over

A model was also constructed for those aged 50 years and over using SAHOS data only, which examined the demographic characteristics associated with self-reported osteoporosis and included year within the model. Increasing age, female sex, increasing years, work status (home duties, retired, student, other) and income (up to $\$ 50,000$ ) were all significant and associated with self-reporting osteoporosis (data not shown).

A third group of models was then created using NWAHS data and examining other factors associated with osteoporosis. Variables examined at a bivariate level were alcohol risk, smoking, family history, body mass index, physical activity, fracture as a result of a fall from 
a standing height or less over the last year and self-reported rheumatoid arthritis. The results of the multivariate analysis are in Table 3.

\begin{tabular}{|c|c|c|c|c|c|c|}
\hline \multirow[b]{2}{*}{ Group two } & \multicolumn{2}{|c|}{ SAHOS self-report } & \multicolumn{2}{|c|}{ NWAHS self-report } & \multicolumn{2}{|c|}{ NWAHS DXA } \\
\hline & OR & $\mathrm{p}$-value & OR & $\mathrm{p}$-value & OR & p-value \\
\hline \multicolumn{7}{|l|}{ Sex } \\
\hline Male & 1.00 & & 1.00 & & 1.00 & \\
\hline Female & 4.44 & $<0.001$ & 5.50 & $<0.001$ & 1.94 & $<0.001$ \\
\hline Age & 1.04 & $<0.001$ & 1.03 & 0.020 & 1.09 & $<0.001$ \\
\hline \multicolumn{7}{|l|}{ Work status } \\
\hline Full time & 1.00 & & 1.00 & & & \\
\hline Part time & 1.16 & 0.46 & 1.12 & 0.823 & & \\
\hline Home duties & 1.72 & 0.003 & 0.93 & 0.934 & & \\
\hline Unemployed & 2.05 & 0.035 & 3.04 & 0.015 & & \\
\hline Retired & 1.75 & 0.002 & 2.67 & 0.034 & & \\
\hline Student & 3.25 & 0.018 & - & - & & \\
\hline Other & 6.08 & $<0.001$ & 2.57 & 0.180 & & \\
\hline Not stated & - & - & 4.69 & 0.081 & & \\
\hline \multicolumn{7}{|l|}{ Income } \\
\hline$\$ 80,001$ and more & 1.00 & & & & & \\
\hline$\$ 60,001-\$ 80,000$ & 1.31 & 0.295 & & & & \\
\hline$\$ 50,001-\$ 60,000$ & 1.14 & 0.632 & & & & \\
\hline$\$ 40,001-\$ 50,000$ & 1.87 & 0.012 & & & & \\
\hline$\$ 30,001-\$ 40,000$ & 1.50 & 0.106 & & & & \\
\hline$\$ 20,001-\$ 30,000$ & 1.55 & 0.051 & & & & \\
\hline$\$ 12,001-\$ 20,000$ & 1.60 & 0.038 & & & & \\
\hline Up to $\$ 12,000$ & 1.28 & 0.272 & & & & \\
\hline Not stated & 1.18 & 0.465 & & & & \\
\hline \multicolumn{7}{|l|}{ Martial status } \\
\hline Married/de facto & & & & & 1.00 & \\
\hline Separated/divorced & & & & & 0.80 & 0.345 \\
\hline Widowed & & & & & 1.28 & 0.253 \\
\hline Never married & & & & & 1.90 & 0.043 \\
\hline Not stated & & & & & 0.86 & 0.903 \\
\hline
\end{tabular}

Table 2. Logistic regression analysis of osteoporosis prevalence, SAHOS and NWAHS selfreport and NWAHS DXA, age 50 years and over 
For both self-report and DXA, non-smokers were more likely to have osteoporosis. Those with a low to high risk of harm from alcohol and with a first degree relative with osteoporosis were more likely to self-report that they had osteoporosis whereas those undertaking lower levels of activity were more likely to have low bone density. Those with a higher body mass index were less likely to have a low bone density (Table 3).

\begin{tabular}{|c|c|c|c|c|}
\hline \multirow[b]{2}{*}{ Group three } & \multicolumn{2}{|c|}{ NWAHS self-report } & \multicolumn{2}{|c|}{ NWAHS DXA } \\
\hline & OR & p-value & OR & $\mathrm{p}$-value \\
\hline BMI & & & 0.82 & $<0.001$ \\
\hline \multicolumn{5}{|l|}{ Alcohol risk } \\
\hline Non drinker/no risk & 1.00 & & & \\
\hline Low to high risk & 1.54 & 0.025 & & \\
\hline Not stated & 1.34 & 0.593 & & \\
\hline \multicolumn{5}{|l|}{ Smoking } \\
\hline Current smoker & 1.00 & & 1.00 & \\
\hline Ex smoker & 1.21 & 0.629 & 1.13 & 0.637 \\
\hline Non smoker & 2.37 & 0.026 & 1.80 & 0.020 \\
\hline \multicolumn{5}{|c|}{ Family history of osteoporosis } \\
\hline No & 1.00 & & 1.00 & \\
\hline First degree relative & 3.66 & $<0.001$ & 1.43 & 0.095 \\
\hline Don't know & 2.73 & $<0.001$ & 1.45 & 0.037 \\
\hline Not stated & 1.13 & 0.851 & 2.20 & 0.124 \\
\hline \multicolumn{5}{|l|}{ Physical activity } \\
\hline High exercise & & & 1.00 & \\
\hline Moderate exercise & & & 1.71 & 0.144 \\
\hline Low exercise & & & 2.07 & 0.042 \\
\hline Sedentary & & & 2.15 & 0.034 \\
\hline Not stated & & & 2.40 & 0.027 \\
\hline
\end{tabular}

Table 3. Logistic regression analysis of other factors associated with osteoporosis, NWAHS self-report and DXA, age 50 years and over

Finally a fourth set of models combined both demographic and other relevant factors associated with osteoporosis, for the data obtained from the NWAHS. Increasing age and female sex remained significant for both models, while those with a higher body mass index were less likely to have a lower bone density and those with self-reported osteoporosis were more likely to have family members with the condition. The work status categories, unemployed and retired, also remained significant for self-reported osteoporosis (Table 4). 


\begin{tabular}{|l|c|c|c|c|}
\hline & \multicolumn{2}{|c|}{ NWAHS self-report } & \multicolumn{2}{c|}{ NWAHS DXA } \\
\hline Group four & OR & p-value & OR & p-value \\
\hline Sex & & & & \\
\hline Male & 1.00 & & 1.00 & \\
\hline Agemale & 4.71 & $<\mathbf{0 . 0 0 1}$ & 2.13 & $<\mathbf{0 . 0 1}$ \\
\hline BMI & 1.03 & $\mathbf{0 . 0 1 3}$ & 1.10 & $<\mathbf{0 . 0 1}$ \\
\hline Work status & & & 0.82 & $<\mathbf{0 0 1}$ \\
\hline Full time & & & & \\
\hline Part time & 1.00 & & & \\
\hline Home duties & 1.05 & 0.922 & & \\
\hline Unemployed & 0.78 & 0.775 & & \\
\hline Retired & 2.85 & $\mathbf{0 . 0 2 3}$ & & \\
\hline Student & 2.55 & $\mathbf{0 . 0 4 4}$ & & \\
\hline Other & - & - & & \\
\hline Not stated & 2.19 & 0.275 & & \\
\hline Family history & 6.22 & $\mathbf{0 . 0 2 3}$ & & \\
\hline No & & & & \\
\hline First degree relative & 3.24 & $<\mathbf{0 . 0 0 1}$ & & \\
\hline Don't know & 2.17 & $\mathbf{0 . 0 0 1}$ & & \\
\hline Not stated & 0.97 & 0.962 & & \\
\hline
\end{tabular}

Table 4. Overall models demographic and other factors associated with osteoporosis, NWAHS, age 50 years and over

\section{Discussion}

The results of this analysis indicate that while determining the population prevalence of osteoporosis remains a difficult issue, there is a role for self-report to play in the monitoring of osteoporosis prevalence over time. At this time, DXA scans are not available to the general population as a screening tool (Davis et al., 2011) and other means of assessing osteoporosis in the population are required. However, it is likely, as this study has shown, that self-reported prevalence will differ from that obtained from bone density assessment. In this study, the prevalence of osteoporosis as measured by DXA among those 50 years and over was lower than the self-reported prevalence but when combined with osteopenia was higher. Sample differences and self-selection to undertake a DXA scan are likely to have contributed to this.

Data from the SAHOS indicate that there has been a significant increase in the self-reported prevalence of osteoporosis over time. It is however difficult to assess whether this is a true increase. Other factors such as a greater awareness of the condition due to marketing campaigns in Australia, particularly in relation to over the counter supplements such as 
vitamin D and calcium, may have played a role in increasing the awareness of the condition. Nevertheless, it can also be argued that this improved awareness, even if it impacts estimates of true prevalence, may still assist in the prevention or management of the condition. Nayak et al. (2010) demonstrated that belief in being susceptible to osteoporosis among older adults, those most at risk of osteoporosis, is low, and the older the respondents were, the less likely they were to believe that osteoporosis is a severe condition. Thus any information or advertising may assist patient education. It is also of interest that the results of DXA scans are not immune to errors in self-report with Cadarette et al. (2007) demonstrating that while there was minimal error in self-reporting that a DXA scan had been undertaken, the self-reporting of results was poor, again providing an underestimate of osteoporosis prevalence. The understanding of these results could however be improved by providing them in writing (Brask-Lindemann et al., 2011). This again highlights issues of patient knowledge and understanding of the condition.

Consequently, in recent years, there has been an increased focus on functional health literacy of the population, which is considered to be the ability of people to read, analyse and take action with regard to both oral and written information obtained in the health care setting (Nielsen-Bohlman et al. 2004). It has been acknowledged that those with low or limited functional health literacy are more likely to have adverse health outcomes, not undertake preventive health behaviours, have premature mortality and higher health-care costs. In addition, people with lower functional health literacy are less likely to undertake active management of their condition (Berkman et al., 2004; De Walt et al., 2005). Unpublished analysis of other data obtained using the SAHOS has indicated that $70 \%$ of those with doctor-diagnosed osteoporosis had a low health literacy, further supporting the view that despite the method used to assess osteoporosis prevalence, inaccuracies in the reporting of the condition may occur, which has implications for management of the condition.

While understanding of the condition and reporting of prevalence is variable, it is of note that there remained a general consistency in the variables that were associated with osteoporosis prevalence, and these are supported by previous work. Genetic factors have been shown to contribute to osteoporosis (Harvey \& Cooper, 2003; Marini \& Brandi, 2010; Recker \& Deng, 2002), thus family history of osteoporosis is an important factor. Sex and age are also significant covariates (Cawthon, 2011; Keen, 2007; Werner, 2003) and these variables are strongly evident during multivariate modelling. Varenna et al. (1999) determined that higher levels of education were associated with a lower risk of osteoporosis and lower income levels and unemployment have been associated with a greater risk of hip fracture (Farahmand et al., 2000). Low body mass index, previous low trauma fracture, rheumatoid arthritis, physical activity, smoking and excessive alcohol consumption have all been identified as risk factors for osteoporosis (Keen, 2007). Despite the fact that many of these variables were self-report, the associations with osteoporosis all occurred in the expected manner, except for smoking, where non-smokers were more likely to have a lower bone density and to self-report osteoporosis. Smokers are more likely to be from lower socioeconomic groups (Scollo \& Winstanley, 2008) which are also groups with a lower level of health literacy (Barber et al., 2009). Thus this group may be less likely to undergo a DXA scan and self-report osteoporosis, as they have a poorer understanding of the condition.

The consequences of osteoporosis in terms of fracture also need to be considered. The overall lack of awareness of osteoporosis within the population also extends to a lack of 
understanding of the risk of a prior fracture in relation to the occurrence of subsequent fractures (Center et al., 2007). Targeted self-management courses for osteoporosis have demonstrated an improved understanding of osteoporosis and related behaviours in the short term (Francis et al., 2009; Laslett et al., 2011) and in Australia, approximately $40 \%$ of those with osteoporosis are more likely to use complementary and alternative medicines, which includes vitamin D and calcium (Armstrong el al., 2011). But despite public campaigns promoting better nutrition and increasing the awareness of osteoporosis, Pasco et al. (2000) demonstrated that women did not achieve the required calcium intake and Czernichow et al. (2010) have shown that the vitamin D intake among postmenopausal women with osteoporosis in France is significantly lower than recommended doses.

As highlighted in this study, similar factors were associated with osteoporosis prevalence, notwithstanding the method of data collection. Thus, surveillance can play a role in the ability to target information, identify at-risk groups and evaluate the impact of health promotion programs. It is however evident that there is a continued need to further explore means of adequately ascertaining the prevalence of osteoporosis and to improve the understanding of the condition in the population.

\section{Conclusion}

While prevalence estimates of osteoporosis vary within the population according to data collection method, generally there are consistent covariates associated with osteoporosis, which are important for the targeting of health promotion campaigns. In the absence of clinical testing, the monitoring of the prevalence of osteoporosis using self-report has a role to play in the prevention and management of the condition.

\section{Acknowledgment}

The authors would like to acknowledge all of the SAHOS participants over the past 16 years and all of the participants in the NWAHS.

Tiffany Gill is currently a National Health and Medical Research Council Early Career fellow to Fellow (Australian Public Health, ID 1013552).

\section{References}

Armstrong, A.R., Thiébaut, S.P., Brown, L.J. \& Nepal, B. (2011). Australian Adults Use Complementary and Alternative Medicine in the Treatment of Chronic Illness: A National Study. Australian and New Zealand Journal of Public Health, Vol. 35, No. 4, pp. 384-390, ISSN 1326-0200

Australian Bureau of Statistics. (2003). National Health Survey: Users Guide, 2001. Cat no 4363.0.55.001, ABS, Canberra, Australia, Retrieved from http://www.abs.gov.au/AUSSTATS/abs@.nsf/Lookup/4363.0.55.001Main+Featu res12001?OpenDocument

Australian Bureau of Statistics. (2006). National Health Survey: Users Guide, 2004-05. Cat no 4363.0.55.001, ABS, Canberra, Australia, Retrieved from http://www.ausstats.abs.gov.au/ausstats/subscriber.nsf/0/A58E031838C37F81C A257141000F1AAF/\$File/4363055001_2004-05.pdf 
Australian Bureau of Statistics. (2007). 2006 Census of Population and Housing, South Australia. Cat no 2068.0 - 2006 Census Tables, Australian Bureau of Statistics, Retrieved from http://www.abs.gov.au

Australian Institute of Health and Welfare. (2011). A Snapshot of Osteoporosis in Australia. Arthritis series no. 15. Cat. No. PHE 137. AIHW, ISBN 978-1-74249-131-8, Canberra, Australia

Barber, M.N., Staples, M., Osborne, R.H., Clerehan, R., Elder, C. \& Buchbinder, R. (2009). Up to a Quarter of the Australian Population May Have Suboptimal Health Literacy Depending Upon the Measurement Tool: Results From a Population-Based Survey. Health Promotion International, Vol. 24, No. 3, pp. 252-261, ISSN 0957-4824

Bergmann, M.M., Jacobs, E.J., Hoffmann, K. \& Boeing, H. (2004): Agreement of Self-reported Medical History: Comparison of an In-person Interview with Self-administered Questionnaire. European Journal of Epidemiology, Vol. 19, No. 5, pp. 411-416, ISSN 0393-2990

Berkman, N.D., DeWalt, D.A., Pignone, M.P., Sheridan, S.L., Lohr, K.N., Lux, L., Sutton, S.F., Swinson, T. \& Bonito, A.J. (2004). Literacy and Health Outcomes. AHRQ Publication No. 04-E007-1, Agency for Healthcare Research and Quality, ISBN 1-58763-142-3, Rockville, Md, USA

Borgström F. \& Kanis, J.A. (2008). Health Economics of Osteoporosis. Best Practice \& Research Clinical Endocrinology \& Metabolism, Vol. 22, No. 5, pp. 885-900, ISSN 1521-690X

Box, G.E.P. \& Tidwell, P.W. (1962). Transformation of the independent variables. Technometrics, Vol. 4, No. 4, pp. 531-550, ISSN 0040-1706

Brask-Lindemann, D., Cadarette, S.M., Eskildsen, P. \& Abrahamsen, B. (2011). Osteoporosis Pharmacotherapy Following Bone Densitometery: Importance of Patient Beliefs and Understanding of DXA Results. Osteoporosis International, Vol. 22, No. 5, pp. 1493-1501, ISSN 0937-941X

Cadarette, S.M., Beaton, D.E., Gignac, M.A., Jaglal, S.B., Dickson, L. \& Hawker, G.A. (2007). Minimal Error in Self-report of Having Had DXA, But Self-Report of its Results Was Poor. Journal of Clinical Epidemiology, Vol. 60, No. 12, pp. 1306-1311, ISSN 08954356

Campostrini, S. (2003). Surveillance Systems and Data Analysis: Continuously Collected Behavioural Data. British and American Examples, In: Global Behavioral Risk Factor Surveillance, D. McQueen \& P. Puska, (Eds.), 47-56, Kluwer Academic, ISBN 0-30647777-7, New York, USA

Cawthon, P. (2011). Gender Differences in Osteoporosis and Fractures. Clinical Orthopaedics and Related Research, Vol. 469, No. 7, pp. 1900-1905, ISSN 0009-921X

Center, J.R., Bliuc, D., Nguyen, N.D., Nguyen, T.V. \& Eisman, J.A. (2011). Osteoporosis Medication and Reduced Mortality Risk in Elderly Women and Men. Journal of Clinical Endocrinology and Metabolism, Vol. 96, No. 4, pp. 1006-1014, ISSN 0021972X

Center, J.R., Bliuc, D., Nguyen, T.V. \& Eisman, J.A. (2007). Risk of Subsequent Fracture After Low-Trauma Fracture in Men and Women. Journal of the American Medical Association, Vol. 297, No. 4, pp.387-394, ISSN 0098-7484

Chatfield, C. (2004). The Analysis of Time Series. An Introduction. $6^{\text {th }}$ ed., Chapman \& Hall/CRC, ISBN 1-58488-317-0, Boca Raton, Florida 
Compston, J., Cooper, A., Cooper, C., Francis, R., Kanis, J.A., Marsh, D., McCloskey, E.V., Reid, D.M., Selby, P., Wilkins, M., on behalf of the National Osteoporosis Guideline Group (NOGG). (2009). Guidelines for the Diagnosis and Management of Osteoporosis in Postmenopausal Women and Men from the age of 50 years in the UK. Maturitas, Vol. 62, No. 2, pp. 105-108, ISSN 0378-5122

Cooper, C. (1997). The Crippling Consequences of Fractures and Their Impact on Quality of Life. American Journal of Medicine, Vol. 103, No. 2A, pp.12S-19S, ISSN 0002-9343

Czernichow, S., Fan, T., Nocea, G. \& Sen, S.S. (2010). Calcium and Vitamin D Intake by Postmenopausal Women with Osteoporosis in France. Current Medical Research $\mathcal{E}$ Opinion, Vol. 26, No 7, pp. 1667-1674, ISSN 0300-7995

Davis, S.R., Kirby, C., Weekes, A., Lanzafame, A. \& Piterman, L. (2011). Simplifying Screening for Osteoporosis in Australian Primary Care: the Prospective Screening for Osteoporosis; Australian Primary Care Evaluation of Clinical Tests (PROSPECT) Study. Menopause, Vol. 18, No. 1, pp. 53-59, ISSN 1072-3714

De Walt, D.A., Berkman, N.D., Sheridan, S., Lohr, K.N. \& Pignone, M.P. (2005). Literacy and health outcomes: a systematic review of the literature, Journal of General Internal Medicine, Vol. 19, No. 12, pp.1228-1239, ISSN 0884-8734

Dillman, D.A. (1999). Mail and Other Self-administered Surveys in the 21 ${ }^{\text {st }}$ Century: the Beginning of a New Era. The Gallup Research Journal, Vol. 2, No. 1, pp. 121-140

Dillman, D.A., Smyth, J.D. \& Christian, L.M. (2009). Internet, Mail and Mixed-mode Surveys. The Tailored Design Method. 3rd ed. John Wiley and Sons, ISBN 978-0-471-69868-5, New Jersey, USA

Eisman, J.A., Clapham, S. \& Kehoe, L., Australian Bone Care Study (2004). Osteoporosis Prevalence and Levels of Treatment in Primary Care: the Australian BoneCare Study. Journal of Bone and Mineral Research, Vol. 19, No. 12, pp. 1969-1975, ISSN 0884-0431

Elliot-Gibson, V., Bogoch, E.R., Jamal, S.A. \& Beaton, D.E. (2004). Practice Patterns in the Diagnosis and Treatment of Osteoporosis After a Fragility Fracture: A Systematic Review. Osteoporosis International, Vol. 15, No. 10, pp. 767-778, ISSN 0937-941X

Farahmand, B., Persson, P.-G., Michaelsson, K., Baron, J., Parker, M., Ljunghall, S., Swedish Hip Fracture Group. (2000). Socio-economic Status, Marital Status and Hip Fracture Risk: A Population-Based Case-Control Study. Osteoporosis International, Vol. 11, No. 9, pp. 803-808, ISSN 0937-941X

Francis, K.L., Matthews, B.L., Van Mechelen, W., Bennell, K.L. \& Osborne, R.H. (2009). Effectiveness of a Community-Based Osteoporosis Education and Self-management Course: A Wait List Controlled Trial. Osteoporosis International, Vol. 20, No. 9, pp. 1563-1570, ISSN 0937-941X

Frey, J. H. (1989). Survey Research by Telephone. Sage Publications, ISBN 978-0803929852 Beverly Hills, USA

Grant, J.F., Taylor, A.W., Ruffin, R.E., Wilson, D.H., Phillips, P.J., Adams, R.J.T., Price, K., \& the North West Adelaide Health Study Team. (2009). Cohort Profile: The North West Adelaide Health Study (NWAHS). International Journal of Epidemiology, Vol. 38, No. 9, pp. 1479-1486, ISSN 0300-5771

Grant, J.F., Chittleborough, C.R., Taylor, A.W., Dal Grande, E., Wilson, D.H., Phillips, P.J., Adams, R.J., Cheek, J.A., Price, K., Gill T., Ruffin, R.E., \& the North West Adelaide 
Health Study Team. (2006). The North West Adelaide Health Study: Detailed Methods and Baseline Segmentation of a Cohort for Selected Chronic Diseases. Epidemiologic Perspectives E Innovations, Vol. 3, (April 12 2006), pp. 4. ISSN 17425573

Haentjens, P., Magaziner, J., Colón-Emeric, C.S., Vanderschueren, D., Milisen, K., Velkeniers, B. \& Boonen, S. (2010). Meta-analysis: Excess Mortality After Hip Fracture Among Older Men and Women. Annals of Internal Medicine, Vol. 152, No. 6, pp. 380-390, ISSN 0003-4819

Harvey, N. \& Cooper, C. (2003). Determinants of Fracture Risk in Osteoporosis. Current Rheumatology Reports, Vol. 5, No. 1, pp. 75-81, ISSN 1523-3774

Hodgson, S.F., Watts, N.B., Bilezikian, J.P., Clarke, B.L., Gray, T.K., Harris, D.W., Johnston, C.C. Jr., Kleerekoper, M., Lindsay, R., Luckey, M.M., McClung, M.R., Nankin, H.R., Petak S.M., Recker, R.R., AACE Osteoporosis Task Force. (2003). American Association of Clinical Endocrinologists Medical Guidelines for Clinical Practice for the Prevention and Treatment of Postmenopausal Osteoporosis: 2001 Edition, With Selected Updates for 2003. Endocrine Practice, Vol. 9, No. 6, pp. 544-564, ISSN 1530891X

Hosmer, D.W. \& Lemeshow, S. (2000). Applied Logistic Regression, 2nd ed., J Wiley and Sons, ISBN 0-471-35632-8, New York, USA

International Union for Health Promotion and Education World Alliance for Risk Factor Surveillance Global Working Group. (2011). White Paper on Surveillance and Health Promotion, International Union for Health Promotion and Education, Geneva, Switzerland, Retrieved from http://www.iuhpe.org/uploaded/Activities/Scientific_Affairs/GWG/WARFS_w hite_paper_draft_may_2011.pdf

Keen, R. (2007). Osteoporosis: Strategies for Prevention and Management. Best Practice $\mathcal{E}$ Research Clinical Rheumatology, Vol. 21, No. 1, pp. 109-122, ISSN 1521-6942

Laslett, L.L., Lynch, J., Sullivan, T.R. \& McNeil, J.D. (2011). Osteoporosis Education Improves Osteoporosis Knowledge and Dietary Calcium: Comparison of a 4 Week and a One-Session Education Course. International Journal of the Rheumatic Diseases, Vol. 14, No. 3, pp. 239-247, ISSN 1756-1841

Marini, F. \& Brandi, M.L. (2010). Genetic Determinants of Osteoporosis: Common Basis to Cardiovascular Disease. International Journal of Hypertension, Mar 25, doi:10.4061/2010/394579, ISSN 2090-0392

McQueen, D.V. (2003). Perspectives on Global Risk Factor Surveillance. Lessons Learned and Challenges Ahead, In: Global Behavioral Risk Factor Surveillance, D. McQueen \& P. Puska, (Eds.), pp. 233-245, Kluwer Academic, ISBN 0-306-47777-7, New York, USA

National Heart Foundation of Australia. (1989). Risk Factor Prevalence Study. Survey No. 3 1989. National Hearth Foundation, ISBN 9780909 47527 7, Canberra, Australia

Nayak, S., Roberts, M.S., Chang C-C.H. \& Greenspan, S.L. (2010). Health Beliefs About Osteoporosis and Osteoporosis Screening in Older Women and Men. Health Education Journal, Vol. 69, No. 3, pp. 267-276, ISSN 0017-8969 
Nielsen-Bohlman, L., Panzer, A. \& Kindig D. (Eds.). (2011). Committee on Health Literacy. A prescription to end confusion, ISBN 0-309-52926-3, National Academies Press, Washington, DC, USA

Pasco, J.A., Sanders, K.M., Henry, M.J., Nicholson, G.C., Seeman, E. \& Kotowicz, M.A. (2000). Calcium Intakes among Australian Women: Geelong Osteoporosis Study. Australian and New Zealand Journal of Medicine, Vol. 30, No. 1, pp.21-27, ISSN 00048291

Rachner, P.D., Khosla, S. \& Hofbauer, L.C. (2011). Osteoporosis: Now and the Future. Lancet, Vol. 377, No. 9773, pp. 1276-1287, ISSN 0140-6736

Recker, R.R. \& Deng, H.W. (2002). Role of Genetics in Osteoporosis. Endocrine Journal, Vol. 17, No. 1, pp. 55-66, ISSN 1355-008X

Royal Australian College of General Practitioners. (2010). Clinical Guideline for the Prevention and Treatment of Osteoporosis in Postmenopausal Women and Older Men. February 2010, Royal Australian College of General Practitioners, ISBN 978-0-86906-306-4, Melbourne, Australia

Robertson, B., Sinclair, M., Forbes, A., Kirk, M., \& Fairley, C. K. (2000). The Effect of an Introductory Letter on Participation Rates Using Telephone Recruitment. Australian and New Zealand Journal of Public Health, Vol. 24, No. 5, pp. 552, ISSN 1326-0200

Sacks, J.J., Harrold, L.R., Helmick, C.G., Gurwitz, J.H., Emani, S. \& Yood, R.A. (2005). Validation of a Surveillance Case Definition for Arthritis. Journal of Rheumatology, Vol. 32, No. 2, pp. 340-347, ISSN 0315-162X

Sànchez-Riera, L., Wilson, N., Nolla J.M., Macara, M., Chen, J.S., Sambrook, P.N., Hernández, C.S. \& March, L. (2010). Osteoporosis and Fragility Fractures. Best Practice and Research Clinical Rheumatology, Vol. 24, No. 6, pp. 793-810, ISSN 15216942

Schonlau, M., Fricker, R.D., Elliott, M.N. (2002). Conducting Research Surveys via Email and the Web, Rand, ISBN 978-0833031105, New York, USA

Scollo, M.M. \& Winstanley, M.H. (Eds.). (2008). Tobacco in Australia: Facts and Issues. $3^{\text {rd }}$ ed. Cancer Council Victoria, Melbourne, Australia, Retrieved from http://www.tobaccoinaustralia.org.au

Unnanuntana, A., Gladnik, B.P., Donnelly, E., \& Lane, J.M. (2010). The Assessment of Fracture Risk. Journal of Bone and Joint Surgery. American Volume, Vol. 92, No. 3, pp. 743-753, ISSN 0021-9355

Varenna, M., Binelli, L., Zucchi, F., Ghringhelli, D., Gallazzi, M., \& Sinigaglia, L. (1999). Prevalence of Osteoporosis by Educational Level in a Cohort of Post-menopausal Women. Osteoporosis International, Vol. 9, No. 3, pp. 236-241, ISSN 0937-941X

Werner, P. (2003). Self Reported Prevalence and Correlates of Osteoporosis: Results from a Representative Study in Israel. Archives of Gerontology and Geriatrics, Vol. 37, No. 3 pp. 277-292, ISSN 0167-4943

Wilson, D.H. (2003). Comparison of Surveillance Data on Metropolitan and Rural Health. Diabetes in Southern Australia as an Example, In: Global Behavioral Risk Factor Surveillance, D. McQueen \& P. Puska, (Eds.), 95-117, Kluwer Academic, ISBN 0-30647777-7, New York, USA 
World Health Organization. (1994). Assessment of Fracture Risk and its Application to Screening for Postmenopausal Osteoporosis. Technical Report Series 843, WHO, ISBN 92-41208430, Geneva, Switzerland

Yaffee, R. \& McGee, M. (2000). Introduction to Time Series Analysis and Forecasting With Applications of SAS and SPSS, Academic Press, ISBN 978-0-12-767870-2, San Diego, USA 


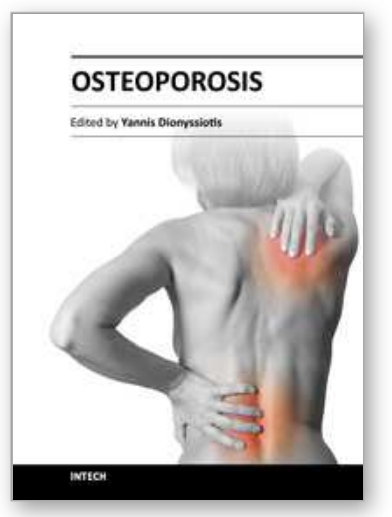

\author{
Osteoporosis \\ Edited by PhD. Yannis Dionyssiotis
}

ISBN 978-953-51-0026-3

Hard cover, 864 pages

Publisher InTech

Published online 24, February, 2012

Published in print edition February, 2012

Osteoporosis is a public health issue worldwide. During the last few years, progress has been made concerning the knowledge of the pathophysiological mechanism of the disease. Sophisticated technologies have added important information in bone mineral density measurements and, additionally, geometrical and mechanical properties of bone. New bone indices have been developed from biochemical and hormonal measurements in order to investigate bone metabolism. Although it is clear that drugs are an essential element of the therapy, beyond medication there are other interventions in the management of the disease. Prevention of osteoporosis starts in young ages and continues during aging in order to prevent fractures associated with impaired quality of life, physical decline, mortality, and high cost for the health system. A number of different specialties are holding the scientific knowledge in osteoporosis. For this reason, we have collected papers from scientific departments all over the world for this book. The book includes up-to-date information about basics of bones, epidemiological data, diagnosis and assessment of osteoporosis, secondary osteoporosis, pediatric issues, prevention and treatment strategies, and research papers from osteoporotic fields.

\title{
How to reference
}

In order to correctly reference this scholarly work, feel free to copy and paste the following:

Tiffany K. Gill, Anne W. Taylor, Julie Black and Catherine L. Hill (2012). Self-Reported Prevalence of Osteoporosis in Australia, Osteoporosis, PhD. Yannis Dionyssiotis (Ed.), ISBN: 978-953-51-0026-3, InTech, Available from: http://www.intechopen.com/books/osteoporosis/self-reported-prevalence-of-osteoporosis-inaustralia

\section{INTECH}

open science | open minds

\section{InTech Europe}

University Campus STeP Ri

Slavka Krautzeka 83/A

51000 Rijeka, Croatia

Phone: +385 (51) 770447

Fax: +385 (51) 686166

www.intechopen.com

\section{InTech China}

Unit 405, Office Block, Hotel Equatorial Shanghai

No.65, Yan An Road (West), Shanghai, 200040, China 中国上海市延安西路65号上海国际贵都大饭店办公楼 405 单元

Phone: +86-21-62489820

Fax: +86-21-62489821 
(C) 2012 The Author(s). Licensee IntechOpen. This is an open access article distributed under the terms of the Creative Commons Attribution 3.0 License, which permits unrestricted use, distribution, and reproduction in any medium, provided the original work is properly cited. 